\title{
COLOR INTENSITY AND ANTIOXIDATIVE CAPACITY OF FOUR NATURAL MONOFLORAL HONEY FROM MALDA, INDIA
}

\author{
SURAJIT ROY, SHYAMAPADA MANDAL* \\ Laboratory of Microbiology and Experimental Medicine, University of Gour Banga, Mokdumpur, Malda, West Bengal, \\ India. Email: samtropmed@gmail.com
}

Received: 29 May 2019, Revised and Accepted: 09 July 2019

\section{ABSTRACT}

Objective: The objective of the study was to explore the color intensity and antioxidative capacity of mango honey available from local niches, in and around Malda, West Bengal, India.

Methods: Four mango honey samples: LMH1, LMH2, LMH3, and LMH4, were collected from bee hives, in and around Malda, India, and were subjected to determine the color intensity and antioxidative capacity in 2, 2-diphenyl-1-picrylhydrazyl system.

Results: The honey samples tested had light to dark color variation with color intensity values of 583.59-1842.84 mAU. The total phenolic content (TPC) of the honey samples ranged from 434.52 to $1450.74 \mu$ g gallic acid equivalents/ml, while the total flavonoids content (TFC) ranged 39.4-72.67 mg quercetin equivalents/100 g of honey. The honey samples displayed antioxidative activity (AOA) with 9.91-76\% inhibition capacity, and the $\mathrm{IC}_{50}$ values of $8.37-19.38 \mathrm{mg} / \mathrm{ml}$. The color intensity of test honeys displayed positive correlation with the TPC ( $\left.\mathrm{r}=0.907\right)$ and TFC ( $\mathrm{r}=0.863$ ), while negative correlation between honey color intensity and $\mathrm{IC}_{50}$ values $(\mathrm{r}=-0.955)$ was recorded.

Conclusion: The locally available mango honeys were rich in bioactive components displaying excellent AOA, and thus, the native honey might be utilized as the potential source of natural antioxidant in our part of the globe.

Keywords: Mango honey, Color intensity, $\mathrm{IC}_{50}$ value, Antioxidative capacity, Total phenolics content, Total flavonoids content.

(C) 2019 The Authors. Published by Innovare Academic Sciences Pvt Ltd. This is an open access article under the CC BY license (http://creativecommons. org/licenses/by/4. 0/) DOI: http://dx.doi.org/10.22159/ajpcr.2019.v12i9.34352

\section{INTRODUCTION}

Much attention has been given to consume natural antioxidants, nowadays, as because of the changes in the dietary habit in modern lifestyle [1] and awareness of the unnecessary side effects of the chemical (synthetic) antioxidants. In human body, when the activity of oxidants exceeds the activity of antioxidants and thus antioxidants are favored causing oxidative stress at the cellular levels, which play a role in the pathogenesis and progression of chronic as well as degenerative diseases, such as Alzheimer's disease, atherosclerosis, heart and lung diseases, diabetes, hypertension, and cancer [2,3]. To tackle such a hostile situation, the prime thing is to exogenous administration of antioxidants that comprises micronutrients (Vitamin $\mathrm{C}$ and/ or Vitamin E, plant phenolics). Other antioxidant forms (butylated hydroxytoluene; butylated hydroxyanisole; tert-butyl hydroquinone; and propyl gallate), which might otherwise compromise the DNA, protein or (essential) lipid functionalities, were found hazardous to human health $[1,4]$. However, the natural antioxidants, in dietary materials, have better scavenging properties and are safer and healthier than the synthetic ones [1].

The honey constituents, such as, sugars, vitamins, amino acids, proteins, trace elements, and enzymes (glucose oxidase, diastase, invertase, catalase, and peroxidase) positioned this natural sweetener as a nutritionally therapeutic agent, while its (honey) bioactivities and diverse medicinal properties [5-7] which are mainly due the phenolic compounds, flavonoids, carotenoids, and organic acids present in the honey $[8,9]$.

Honey, being a natural medicine, has been in use since ancient times all over the world to combat different infectious diseases as well as non-infectious diseases [10]. The medicinal property and biological activities, including antioxidative capacity, of natural as well as medicated honey, have been reported from various parts of the world [7,11-13]. It has been reported by earlier authors [14,15] that apart from carbohydrates, honey contains compounds such as phenolic acids, ascorbic acid, flavonoids, tocopherols, enzymes (catalase and superoxide dismutase), reduced glutathione, amino acids, and carotenoids; however, the phenolics and flavonoids in honey play a major role as the antioxidants [12,16]. Ahmed et al. [12] studied that the presence of pigments such as carotenoids and flavonoids was related to color of honey, and dark colored honey possesses a large amount of such kind of pigments with higher antioxidation potential. Sohaimy et al. [17] reported that the honey with high color intensity might be the indicative of the presence of a high amount of phenolic compounds and flavonoids in honeys. Earlier the phytochemical components of honey bee products as well as wild honey have been explored mentioning different health benefits, including the antioxidative capacity $[18,19]$. We also have reported the antibacterial and antioxidative property of two natural honey samples [20]. In the current study, mango honeys from naturally grown bee hives, in and around Malda town, India, were tested to record the antioxidative capacity as well as the color intensity since no scientific data are available on mango honeys from our part of the globe.

\section{METHODS}

\section{Collection of honey samples}

Four natural monofloral (mango: Mangifera indica L.) honey samples: LMH1, LMH2, LMH3, and LMH4, were collected, from four different areas (Kendpukur, Sahapur, Chalandar, and Mahinagar, respectively) of Malda district, West Bengal, India, during the month of February, 2017May 2017. The honey samples were collected by the help of honey collectors, and the identity of the collected honeys was confirmed by the honey collectors depending on the seasonal as well as vegetation variation around the foraging areas of bee hives $[15,20]$. All the honey samples were kept in the dark at room temperature for further study. 
Determination of honey color intensity

The color intensity of honey samples collected was determined following the protocol of Beretta et al. [19]. Briefly, each of the honey samples was diluted to $50 \%(\mathrm{w} / \mathrm{v})$ with double distilled water $\left(45^{\circ} \mathrm{C}-50^{\circ} \mathrm{C}\right)$ and filtered through filter paper (Whatman No.1, Merck), to remove the suspended particles. The absorbance of the honey solution was measured at $450 \mathrm{~nm}$ and $720 \mathrm{~nm}$, using double Ultraviolet (UV)-visible spectrophotometer (Lim 332, Labard Instruchem Pvt., Ltd, India), and the difference between the absorbance was considered as the color intensity, and expressed in mAU (milli absorbance units) [21].

\section{Determination of total phenolics content (TPC)}

The TPC of honey was determined spectrophotometrically by the Folin-Ciocalteu (FCR) technique, following Alzahrani et al. [11]. For this purpose, $200 \mu \mathrm{l}$ of $10 \%$ (v/v; with double distilled water) filtered honey solution was mixed with $500 \mu \mathrm{l}$ of $10 \%$ Folin-Ciocalteu reagent (FCR; with double distilled water) for $5 \mathrm{~min}$, and $1.5 \mathrm{ml}$ of $\mathrm{Na}_{2} \mathrm{CO}_{3}$ solution $(7.5 \%$ with double distilled water) was added and mixed. The reaction mixture was left for $30 \mathrm{~min}$ at room temperature in darkness, and thereafter, absorbencies were read, against a blank (methanol, Folin reagent, and sodium carbonate), using double beam UV-visible spectrophotometer (Lim 332, Labard Instruchem Pvt., Ltd, India), at $725 \mathrm{~nm}$, using gallic acid (GA) calibration curve (concentration range: $\left.10-100 \mu \mathrm{g} / \mathrm{ml} ; \mathrm{R}^{2}=0.9216\right)$. The TPC was expressed as $\mu \mathrm{g}$ of GA equivalents (GAE)/ml of honey ( $\mu \mathrm{g} \mathrm{GAE} / \mathrm{ml}$ ).

\section{Determination of total flavonoids content (TFC)}

The TFC was determined using $\mathrm{AlCl}_{3}$, according to the protocol of Arvouet-Grand et al. [22] with slight modifications. Briefly, $1.5 \mathrm{ml}$ of $2 \%$ $\mathrm{AlCl}_{3}$ in methanol was mixed with an equal volume of honey solution $(1: 3, w / v$, ratio, in methanol). After incubation at room temperature, for $15 \mathrm{~min}$, in darkness, the absorbance of the mixture was measured at $415 \mathrm{~nm}$ against a blank solution (consisting of methanol without $\mathrm{AlCl}_{3}$ ). The TFC was determined using the calibration curve of quercetin (concentration range: $25-150 \mu \mathrm{g} / \mathrm{ml} ; \mathrm{R}^{2}=0.952$ ), and the results were expressed as mg of quercetin equivalents (QE)/100 $\mathrm{g}$ of honey.

\section{Antioxidative activity (AOA) of honey}

The AOA of each of the honey samples was evaluated in 2, 2-diphenyl1-picrylhydrazyl (DPPH) system, which was based on the protocol of Habib et al. [23]. The honey solutions: $3-15 \mathrm{mg} / \mathrm{ml}$ for LMH1 and LMH2, and $6-30 \mathrm{mg} / \mathrm{ml}$ for LMH3 and LMH4, in methanol were prepared, and $0.1 \mathrm{ml}$ of such honey extract (for all honey types of all concentrations) was mixed with $0.3 \mathrm{ml}$ methanol and $0.4 \mathrm{ml} 0.3 \mathrm{mM}$ DPPH in methanol, by shaking, and left for $30 \mathrm{~min}$ in darkness at room temperature. The reduction (inhibition) of DPPH radical was measured by checking the absorbencies of the mixture at $517 \mathrm{~nm}$, against the control prepared with DPPH in methanol without honey, and the radical scavenging activity (RSA) was calculated as the percentage of DPPH radical inhibition, using

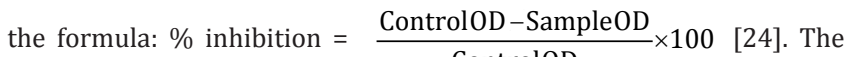
$\mathrm{IC}_{50}$ (half-maximal inhibitory concentration) value of individual honey samples was determined as per the protocol mentioned earlier [24].

\section{Statistical analysis}

The tests were performed in triplicates, and the results have been represented as mean \pm standard deviation. The statistical analyses were done using Microsoft Excel 2016. One-way analysis of variance (ANOVA) was used to determine significant differences $(\mathrm{p}<0.05)$ among utilized parameters of honey samples. The degree of association between color intensity and other variables (TPC, TFC, and $\mathrm{IC}_{50}$ ) was assessed by Pearson's correlation coefficient (r).

\section{RESULTS AND DISCUSSION}

\section{Color intensity of honey}

Among the collected four mango honeys, two (LMH1 and LMH2) were dark amber in color, while the remaining honey samples (LMH3 and LMH4) were light amber in color (Fig. 1). The color intensity test results for honey samples are represented in Table 1; the color intensity ranged

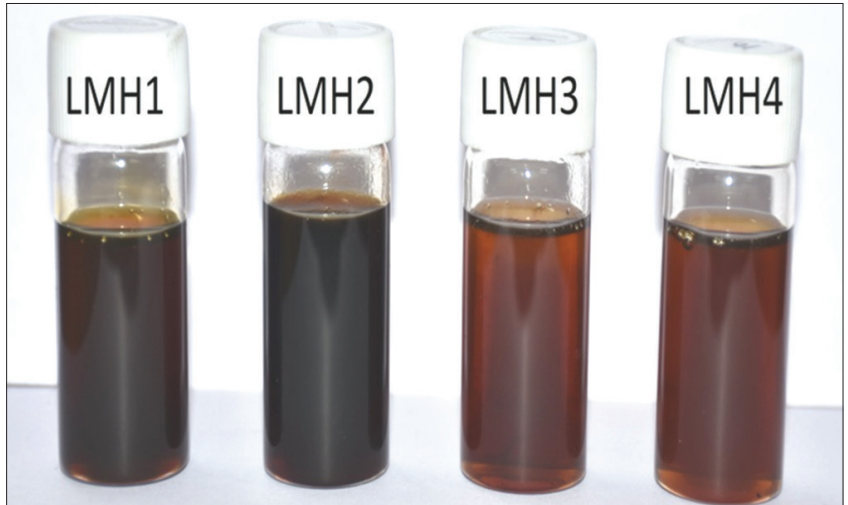

Fig. 1: Color pattern of four locally available monofloral (mango) honey samples procured from different parts of Malda; LMH1: Kendpukur, LMH2: Sahapur, LMH3: Chalandar, LMH4: Mahinagar

Table 1: Color intensity of mango honey collected from Malda, India

\begin{tabular}{lll}
\hline Honey sample & Visual color & Color intensity (mAU) \\
\hline LMH1 & Dark amber & $1842.84 \pm 21.17$ \\
LMH2 & Dark amber & $1021.44 \pm 18.56$ \\
LMH3 & Light amber & $633.32 \pm 3.51$ \\
LMH4 & Light amber & $583.59 \pm 8.08$ \\
\hline
\end{tabular}

from $583.59 \pm 8.08 \mathrm{mAU}$ (for LMH4 honey) to $1842.84 \pm 21.17 \mathrm{mAU}$ (for LMH1 honey).

The honey color intensity is an important parameter for the determination of antioxidant properties of honeys. The color intensity has been demonstrated earlier by several authors around the globe. As has been assessed through visual observation, by Bertoncelj et al. [25], the Slovenian honey color ranged from colorless to dark brown, the acacia (HCI: $70 \mathrm{mAU}$ ) and lime honeys being the brightest to pale yellow, while the chestnut (HCI: $495 \mathrm{mAU}$ ) and fir ( $\mathrm{HCI}: 405 \mathrm{mAU}$ ) honeys being the amber less dark to grey-brown. Islam et al. [26] assessed different monofloral and multifloral, amber to dark amber color, Bangladeshi honeys, and recorded their color intensity ranged from $254 \mathrm{mAU}$ to 2034 mAU. Moniruzzaman et al. [27] reported four Malaysian honey samples with $\mathrm{ABS}_{450}$ values 312-544 mAU, among which, the amber color Tualang honey had the highest color intensity ( $544.33 \pm 11.68 \mathrm{mAU})$. The Polish goldenrod (Solidago virgaurea L.) honey had a low range of color intensity (138-205 mAU), as has been reported by Jasicka-Misiak et al. [28]. Ahmed et al. [12] analyzed 16 honey samples for which color intensity values ranged 386.23-748.83 mAU, and 630-1006.33 mAU for nine honey samples as reported by Nweze et al. [29]. Moloudian et al. [30] investigated on 48 Iranian honeys with color intensity of 25-743 mAU, while Nayik and Nanda [31] recorded the values 18-795 $\mathrm{mAU}$ for 37 honeys of varied floral origin. In the current study, color intensity ranged $1021.44 \pm 18.56-1842.84 \pm 21.17 \mathrm{mAU}$ for dark variety honey, and 583.59 $\pm 8.08-633.32 \pm 3.51 \mathrm{mAU}$ for light variety honey. Such honey color grades with different intensity might be due to variation in floral and geographical origin as well as dissimilarity in the chemical composition of honeys harvested in different seasons.

\section{TPC of honey}

The TPC of the test honey samples is represented in Table 2. The TPC values ranged from $1450.74 \pm 5.98 \mu \mathrm{g} \mathrm{GAE} / \mathrm{ml}$ to $434.52 \pm 5.96 \mu \mathrm{g} \mathrm{GAE} / \mathrm{ml}$; highest TPC content was found in LMH1 (dark variety honey) while the lowest value was seen in LMH4 (light variety honey).

As per the report of Dezmirean et al. [32], the light colored raspberry honey had the lowest amount of total phenolics (148.47 mg GAE/kg), while in the dark colored heather honey the concentration of total phenolics (435.99 $\mathrm{mg} \mathrm{GAE} / \mathrm{kg}$ ) was $\approx 3$-fold higher than that contained 
in raspberry honey. The TPC for Indian honeys has been reported to be ranged from $47 \mathrm{mg} \mathrm{GAE} / 100 \mathrm{~g}$ to $98 \mathrm{mg} \mathrm{GAE} / 100 \mathrm{~g}$ [33], while the sourwood honey contained TPC of $580.03 \pm 0.38 \mathrm{mg} \mathrm{GAE} / \mathrm{kg}$ [27]. The TPC for four Malayan monofloral and multifloral honey samples ranged 186.70-352.73 mg GAE/kg, wherein the Tualang honey had the highest TPC having the highest color intensity (544.33 $\pm 11.68 \mathrm{mAU})$ [27]. Mahnot et al. [34] from Northeastern India reported the TPC of test honey as 74.42-290.68 mg GAE/100 g. Ávila et al. [35] reported the TPC content in Brazilian stingless bee honeys as 220.4-708.1 mg of GAE $/ \mathrm{kg}$. In the current study, highest TPC value $(1450.74 \pm 5.98 \mu \mathrm{g} \mathrm{GAE} / \mathrm{ml})$ was measured in the dark variety honey (LMH1 sample), and the lowest TPC $(434.52 \pm 5.96 \mu \mathrm{g} \mathrm{GAE} / \mathrm{ml})$ was found in the light variety honey (LMH4 sample).

\section{TFC of honey}

The quercetin calibration curve in determining TFC is represented in Fig. 2. The TFC of the mango honey tested is shown in Table 2 , with the highest value of $72.67 \pm 0.15 \mathrm{mg}$ $\mathrm{QE} / 100 \mathrm{~g}$, for LMH1 (dark variety) honey, and the lowest value of $39.4 \pm 0.2 \mathrm{mg} \mathrm{QE} / 100 \mathrm{~g}$, for LMH4 honey (light variety). As has been reported by Moniruzzaman et al. [36], the TFC in ten monoflora honey samples from Bangladesh ranged from 11.46 to $116.67 \mathrm{mg}$ catechin $/ \mathrm{kg}$. The TFC values in eight commercial Moroccan carob honeys ranged from $2.26 \mathrm{mg} \mathrm{QE} / 100 \mathrm{~g}$ to $4.79 \mathrm{mg} \quad \mathrm{QE} / 100 \mathrm{~g}$ [37]. Mohamed Al-Farsi [38] from Oman investigated 26 natural honeys and reported highest TFC in Sumer samples in a range between $1613 \mathrm{mg} / \mathrm{kg}$ and $2890 \mathrm{mg} / \mathrm{kg}$, while the TFC in Sidr and multiflora samples ranged $635-1034 \mathrm{mg} / \mathrm{kg}$ and $521-1354$ $\mathrm{mg} / \mathrm{kg}$, respectively. The TFC of five honey samples collected from Bangladesh ranged from 4.67 to $6.25 \mathrm{mg} \mathrm{CE} / 100 \mathrm{~g}$ [39]. It has been reported that the high TFC (43.17 mg QE/kg) was found in the dark colored heather honey, followed by raspberry honey

(15.94- $43.17 \mathrm{mg} \mathrm{QE} / \mathrm{kg}$ ) and multifloral honey (11.95 mg QE/kg), while the lower TFC were recorded in black locust honey $(4.61 \mathrm{mg}$ $\mathrm{QE} / \mathrm{kg}$ ) and linden honey $(8.90 \mathrm{mg} \mathrm{QE} / \mathrm{kg}$ ) honey [32]. Herein, the dark variety of honeys had TFC values of $68.83 \pm 0.21-72.67 \pm 0.15 \mu \mathrm{g}$ $\mathrm{GAE} / \mathrm{ml}$, while the values ranged $39.4 \pm 0.2-45.67 \pm 0.06 \mu \mathrm{g} \mathrm{GAE} / \mathrm{ml}$ for light variety of honeys.

Antioxidative capacity of honey

The antioxidant property of mango honey samples has been determined in the form of antiradical activity in DPPH scavenging system. The percent inhibition (DPPH reduction/radical scavenging) activities for light color honeys (LMH1 and LMH2) are represented in Fig. 3, and for

Table 2: Antioxidative substances and antioxidant activity of mango honey samples $(n=4)$

\begin{tabular}{llll}
\hline $\begin{array}{l}\text { Honey } \\
\text { sample }\end{array}$ & TPC $(\boldsymbol{\mu g}$ GAE $/ \mathbf{m l})$ & TFC $(\mathbf{m g ~ Q e E} / \mathbf{1 0 0} \mathbf{g m})$ & IC $_{\mathbf{5 0}}(\mathbf{m g} / \mathbf{m l})$ \\
\hline LMH1 & $1450.74 \pm 5.98$ & $72.67 \pm 0.15$ & 8.37 \\
LMH2 & $1224.67 \pm 5.96$ & $68.83 \pm 0.21$ & 12.46 \\
LMH3 & $468.15 \pm 11.91$ & $45.67 \pm 0.06$ & 17.08 \\
LMH4 & $434.52 \pm 5.96$ & $39.4 \pm 0.2$ & 19.38 \\
\hline
\end{tabular}

TPC: Total phenolic content; GAE: Gallic acid equivalents; TFC: Total flavonoid content; QeE: Quercetin equivalents; DPPH: 2, 2-diphenyl-1-picrylhydrazyl; IC $_{50}$ : half maximal inhibitory concentration. Values are mean \pm standard deviation

Table 3: Correlation matrix (Pearson correlation coefficients) among different parameters of mango honey samples $(n=4)$

\begin{tabular}{|c|c|c|c|c|}
\hline Pearson correlation & Color intensity $^{\alpha}$ & TPC $^{\beta}$ & $\mathrm{TFC}^{\gamma}$ & $\mathrm{IC}_{50}{ }^{\delta}$ \\
\hline Color intensity $^{\alpha}$ & 1 & & & \\
\hline $\mathrm{TPC}^{\beta}$ & 0.907 & 1 & & \\
\hline $\mathrm{TFC}^{\gamma}$ & 0.863 & 0.988 & 1 & \\
\hline $\mathrm{IC} 50^{\delta}$ & -0.955 & -0.971 & -0.967 & 1 \\
\hline
\end{tabular}

$p$ value $(\alpha, \beta): 0.047$; p value $(\alpha, \gamma): 0.068 ; p$ value $(\alpha, \delta): 0.023 ; p$ value $(\beta$, $\gamma)$ : 0.006; p value $(\beta, \delta): 0.014 ; \mathrm{p}(\gamma, \delta): 0.016$. TPC: Total phenolic content; TFC: Total flavonoid content; $\mathrm{IC}_{50}$ : Half-maximal inhibitory concentration dark color honeys (LMH3 and LMH4) are represented in Fig. 4, while the $\mathrm{IC}_{50}$ values are shown in Table 2. In DPPH system, the scavenging activity of Bangladeshi honeys ranged from $33.6 \%$ to $97.5 \%$ [26], while the values ranged from $44 \%$ to $71 \%$, for Indian honeys [9]. In the current study, the $\mathrm{IC}_{50}$ values of four mango honey samples: LMH1, LMH2, LMH3, and LMH4, have been assessed as 8.37, 12.46, 17.08, and $19.38 \mathrm{mg} / \mathrm{ml}$, respectively. In the instant study, dark colored honey (LMH3 and LMH4) displayed IC $\mathrm{IC}_{50}$ values of $8.37-12.46 \mathrm{mg} / \mathrm{ml}$, while the $\mathrm{IC}_{50}$ values of light colored honeys were in the range of $17.08-19.38 \mathrm{mg} / \mathrm{ml}$.

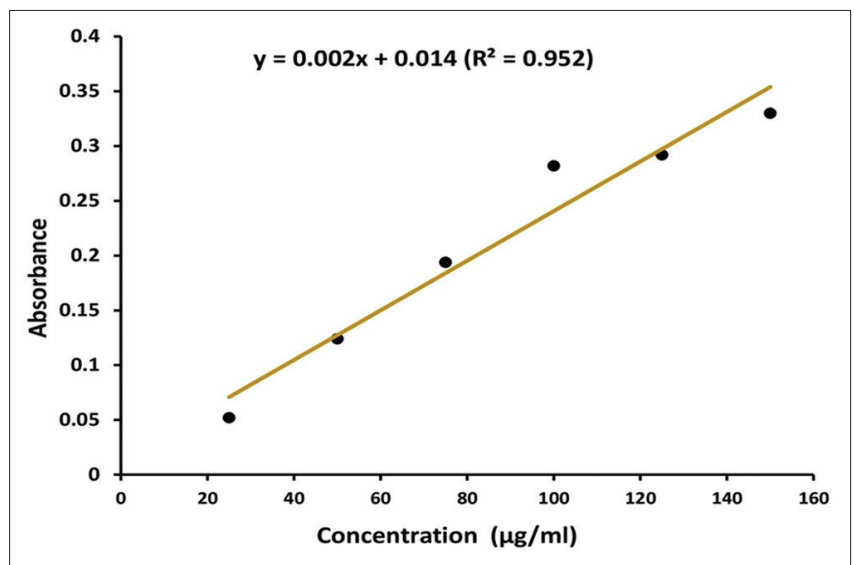

Fig. 2: Quercetin calibration curve for the determination of total flavonoids content in honey samples

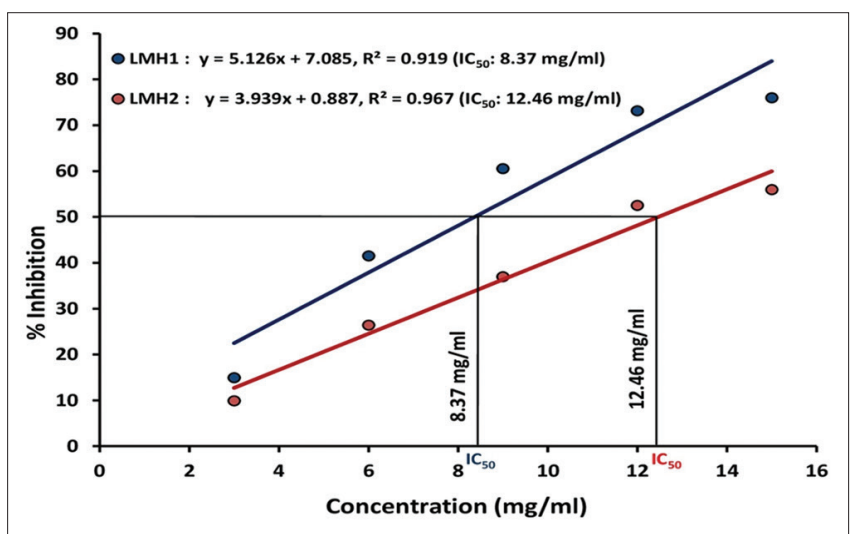

Fig. 3: Antioxidative activity of dark amber color honey (LMH1 and LMH2) in DPPH system; IC $_{50}$ : Half-maximal inhibitory concentration

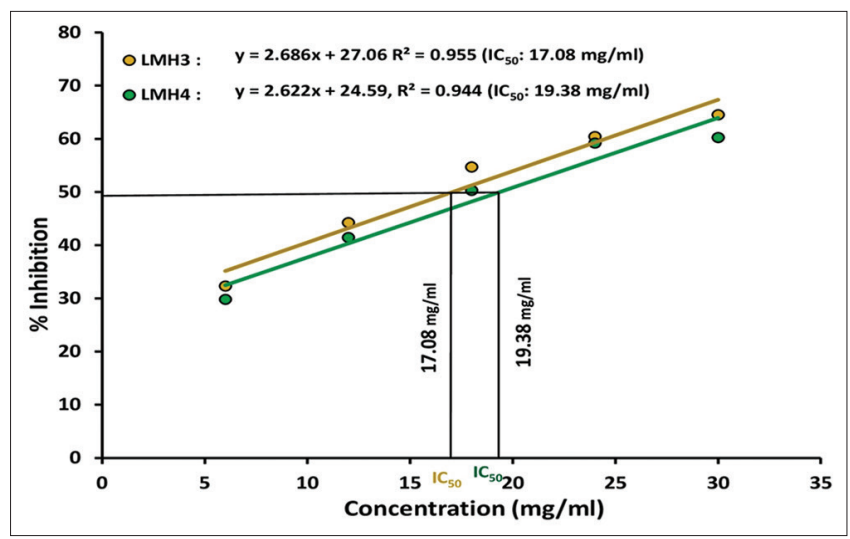

Fig. 4: Antioxidative activity of light amber color honey (LMH1 and LMH2) in DPPH system; IC 5 : Half-maximal inhibitory concentration 
Correlation between honey color intensity and antioxidative profiles

The nature and direction of the correlation between honey color and antioxidative profiles (TPC, TFC, and $\mathrm{IC}_{50}$ ) are represented in Table 3. An immense association exists between the bio-physicochemical agents (color pattern and color intensity, TPC and TFC) and antioxidative capacity (DPPH RSA) of honey, and the dark color honeys (with high color intensity) possessing higher TFC and TPC demonstrated strong AOA, in the instant study. Dezmirean et al. [32] established a positive correlation between the AOA of honeys and the total phenolics and flavonoids contained in the honeys and showed that the phenolics and flavonoids are responsible for the AOA of honey. As has been reported by Khalil et al. [40], there was a positive correlation between the honey color intensity and various antioxidant parameters of Algerian honeys including TFC and DPPH (0.968 and 0.964, respectively) and between TFC and DPPH RSA ( $\mathrm{r}=0.888)$. As has been reported by Islam et al. [26], there were considerable correlations between biochemical and antioxidant factors traced in Bangladeshi honeys; the author demonstrated correlation of honey color pattern/color intensity with TPC ( $\mathrm{r}=0.820)$, TFC ( $\mathrm{r}=0.727)$, and DPPH activity ( $\mathrm{r}=0.948)$, and between TPC and DPPH activity $(r=0.869)$ and TFC and DPPH activity $(\mathrm{r}=0.786)$. A positive correlation between the presence of phenolic compounds and honey color $(r=0.844)$, the honey color and the antioxidant capacity ( $\mathrm{r}=0.675-0.862)$, and phenolics and antioxidant capacity ( $\mathrm{r}=0.615-0.782$ ) have been observed, when analyzed in vitro the Brazilian Pampa biome honey, by Cruz et al. [41]. Among six Romanian honeys (black locust, linden, heather, raspberry, canola, and multifloral) tested, the dark colored heather honey contained highest TPC (435.99 $\mathrm{mg} \mathrm{GAE} / \mathrm{kg}$ ) as well as TFC (43.17 mg QE/ $\mathrm{kg}$ ) values, while the light colored raspberry honey had TPC and TFC values of $148.47 \mathrm{mg}$ GAE/kg-15.94 mg QE/kg, respectively, with respective AOA (in DPPH system) of $35.77 \%$ and $28.9 \%$, for heather honey and raspberry honey [32]. In view of the fact that the honey color reflects, to a certain extent, the content of pigments with antioxidative capacity [42], the current study, for the $1^{\text {st }}$ time, demonstrated a possible correlation between two such factors: Antioxidative capacity (TFC and TPC) and the color intensity of mango honeys available from local niches.

Moniruzzaman et al. [26] reported the tualang honey among four Malaysian honeys, which had the highest color intensity, highest TPC and TFC value had the highest scavenging activity in DPPH system (59.89\%) and concluded that the higher concentrations of phenolic compounds and flavonoids may have been responsible for the higher percentage of radical-scavenging activity. Neupane et al. [43] found a significant correlation between AOA (DPPH RSA) and TPC ( $r=0.992)$ of honey from different altitudes of Nepal Himalayas. The TPC in multifloral Poland honeys ranged $611-990 \mathrm{mg} / \mathrm{kg}$, and in Slovak honeys ranged 703.7-1257.12 mg/kg, while in Serbian forest honeys the TPC ranged 769-1052 mg/kg, and the highest TPC (2962.24 mg/kg) was recorded in buckwheat honey, which had highest AOA, by ABTS (4.63 mmol $/ \mathrm{kg}$ ) [44], as well as by DPPH [45]. The honey color, in the current study, showed a high positive correlation with TPC ( $\mathrm{r}=0.907)$ and TFC ( $\mathrm{r}=0.863)$ values, and also, the high positive correlations $(\mathrm{r}=0.988)$ were achieved between TPC and TFC values of the test honeys, while negative correlations were established between AOA $\left(\mathrm{IC}_{50}\right.$ values) and honey color intensity $(-0.955)$, TPC $(-0.971)$, and TFC (-0.967). Thus, the higher the color intensity, the higher the TPC and TFC values of honey and the lower the $\mathrm{IC}_{50}$ values, the higher the antioxidative activities of the honey.

\section{CONCLUSION}

The mango honeys available in local niches are rich in antioxidative components (flavonoids and phenolics), and thus possess excellent antioxidative capacity, wherein the dark colored honey is superior to the light colored honey. The mango honey might be useful as natural antioxidants, and the people in our part of the globe might get beneficial effects on consuming such natural honeys.

\section{AUTHOR'S CONTRIBUTIONS}

Surajit Roy performed experimental work and wrote the paper; Shyamapada Mandal designed the study, standardized the protocols, wrote and discussed the paper.

\section{CONFLICTS OF INTEREST}

Authors declared that they have no conflicts of interest.

\section{REFERENCES}

1. Anbudhasan P, Surendraraj A, Karkuzhali S, Sathishkumaran P. Natural antioxidants and its benefits. Int J Food Nutr Sci 2014;3:225-32.

2. Li Y, Hu K, Yu Y, Rotenberg SA, Amatore C, Mirkin MV, et al. Direct electrochemical measurements of reactive oxygen and nitrogen species in nontransformed and metastatic human breast cells. J Am Chem Soc 2017;139:13055-62.

3. Boukhenouna S, Wilson MA, Bahmed K, Kosmider B. Reactive oxygen species in chronic obstructive pulmonary disease. Oxid Med Cell Longev 2018;11:1-9.

4. Bouayed J, Bohn T. Exogenous antioxidants double-edged swords in cellular redox state: Health beneficial effects at physiologic doses versus deleterious effects at high doses. Oxid Med Cell Longev 2010;3:228-37.

5. Mandal MD, Mandal S. Honey: Its medicinal property and antibacterial activity. Asian Pac J Trop Biomed 2011;1:154-60.

6. Pannu A, Parle M. Anti-obsessive-compulsive activity of honey. Asian J Pharm Clin Res 2017;10:206-9.

7. Chaiyasut C, Kesika P, Peerajan S, Sivamaruthi BS. The total polyphenolic content and antioxidant properties of various honey and sugars. Asian J Pharm Clin Res 2018;11:467-71.

8. Bogdanov S, Jurendic T, Sieber R, Gallmann P. Honey for nutrition and health: A review. J Am Coll Nutr 2008;27:677-89.

9. Özcan M, Juhaimi FA. Honey as source of natural antioxidants. J Apic Res 2015;54:145-54.

10. Arawwawala LD, Hewageegana HG. Health benefits and traditional uses of honey: A review. J Apictherapy 2017;2:9-14.

11. Alzahrani HA, Alsabehi R, Boukraâ L, Abdellah F, Bellik Y, Bakhotmah BA, et al. Antibacterial and antioxidant potency of floral honeys from different botanical and geographical origins. Molecules 2012;17:10540-9.

12. Ahmed M, Shafiq MI, Khaleeq A, Huma R, Qadir MA, Khalid A, et al. Physiochemical, biochemical, minerals content analysis, and antioxidant potential of national and international honeys in Pakistan. J Chem 2016;13:1-10.

13. Ahmed S, Sulaiman SA, Baig AA, Ibrahim M, Liaqat S, Fatima S, et al. Honey as a potential natural antioxidant medicine: An insight into its molecular mechanisms of action. Oxid Med Cell Longev 2018;2018:8367846.

14. Roodi PA, Moosavi Z, Goli AA, Azizzadeh M, Hosseinzadeh H. Histopathological study of protective effects of honey on subacute toxicity of acrylamide-induced tissue lesions in rats' brain and liver. Iran J Toxicol 2018;12:1-8

15. Stagos D, Soulitsiotis N, Tsadila C, Papaeconomou S, Arvanitis C, Ntontos A, et al. Antibacterial and antioxidant activity of different types of honey derived from mount Olympus in Greece. Int J Mol Med 2018;42:726-34.

16. Deng J, Liu R, Lu Q, Hao P, Xu A, Zhang J, et al. Biochemical properties, antibacterial and cellular antioxidant activities of buckwheat honey in comparison to Manuka honey. Food Chem 2018;252:243-9.

17. Sohaimy SA, Masry SH, Shehata MG. Physicochemical characteristics of honey from different origins. Ann Agric Sci 2015;60:279-87.

18. Kothai S, Jayanthi B. Evaluation of antioxidant and antimicrobial activity of stingless bee propolis (Tetragonula iridipennis) of Tamil Nadu, India. Int J Pharm Pharm Sci 2014;6:81-5.

19. Yap P, Bakar MF. Physicochemical, phytochemical and antimicrobial properties of wild honey collected at mangrove and mountain areas in Sabah, Malaysian Borneo. Int J Pharm Pharm Sci 2014;6:287-92.

20. Roy S, Mandal M, Pal NK, Das MK, Halder D, Sircar B, et al. Exploration of antibacterial and antioxidative property of two natural honey samples from Malda district, India. Transl Med 2016;6:1-5.

21. Beretta G, Granata P, Ferrero M, Orioli M, Facino RM. Standardization of antioxidant properties of honey by a combination of spectrophotometric/fluorimetric assays and chemometrics. Anal Chim Acta 2005;533:185-91

22. Arvouet-Grand A, Vennat B, Pourrat A, Legret P. Standardization of 
propolis extract and identification of principal constituents. J Pharm Belg 1994;49:462-8.

23. Habib HM, Ibrahim WH, Schneider-Stock R, Hassan HM. Camel milk lactoferrin reduces the proliferation of colorectal cancer cells and exerts antioxidant and DNA damage inhibitory activities. Food Chem 2013;141:148-52.

24. Saha A, Mandal S. In vitro assessment of two commercial honey samples for antibacterial and antioxidant activities. Austin J Trop Med Hyg 2015;1:1-5.

25. Bertoncelj J, Doberšek U, Korošec M, Golob T. Evaluation of the phenolic content, antioxidant activity and colour of Slovenian honey. Food Chem 2007; 105:822-8.

26. Islam A, Khalil I, Islam N, Moniruzzaman M, Mottalib A, Sulaiman SA, et al. Physicochemical and antioxidant properties of Bangladeshi honeys stored for more than one year. BMC Complement Altern Med 2012;12:1-10

27. Moniruzzaman M, Sulaiman SA, Khalil MI, Gan SH. Evaluation of physicochemical and antioxidant properties of sourwood and other Malaysian honeys: A comparison with manuka honey. Chem Cent J 2013;7:138.

28. Jasicka-Misiak I, Makowicz E, Stanek N. Chromatographic fingerprint, antioxidant activity, and colour characteristic of Polish goldenrod (Solidago virgaurea L.) honey and flower. Eur Food Res Technol 2018;244:1169-84

29. Nweze JA, Okafor JI, Nweze EI, Nweze JE. Evaluation of physicochemical and antioxidant properties of two stingless bee honeys: A comparison with Apis mellifera honey from Nsukka, Nigeria. BMC Res Notes 2017;10:1-6.

30. Moloudian H, Abbasian S, Nassiri-Koopaei N, Tahmasbi MR, Afzal GA, Ahosseini MS, et al. Characterization and classification of Iranian honey based on physicochemical properties and antioxidant activities, with chemometrics approach. Iran J Pharm Res 2018;17:708-25.

31. Nayik GA, Nanda VA. Chemometric approach to evaluate the phenolic compounds, antioxidant activity and mineral content of different unifloral honey types from Kashmir, India. Food Sci Technol 2016;74:504-13.

32. Dezmirean GI, Mărghitaș LA, Bobiş O, Dezmirean DS, Bonta V, Erler $\mathrm{S}$, et al. Botanical origin causes changes in nutritional profile and antioxidant activity of fermented products obtained from honey. J Agric Food Chem 2012;60:8028-35.

33. Saxena S, Gautam S, Sharma A. Physical, biochemical and antioxidant properties of some Indian honeys. Food Chem 2010;118:391-7.

34. Mahnot NK, Saikia S, Mahanta CL. Quality characterization and effect of sonication time on bioactive properties of honey from North East India. J Food Sci Technol 2019;56:724-36.

35. Ávila S, Hornung PS, Teixeira GL, Malunga LN, Apea-Bah FB, Beux MR, et al. Bioactive compounds and biological properties of Brazilian stingless bee honey have a strong relationship with the pollen floral origin. Food Res Int 2019;123:1-10.

36. Moniruzzaman M, An CY, Rao PV, Hawlader MN, Azlan SA, Sulaiman SA, et al. Identification of phenolic acids and flavonoids in monofloral honey from Bangladesh by high performance liquid chromatography: Determination of antioxidant capacity. BioMed Res Int 2014;14:1-11

37. El-Haskoury R, Kriaa W, Lyoussi B, Makni M. Ceratonia siliqua honeys from Morocco: Physicochemical properties, mineral contents, and antioxidant activities. J Food Drug Anal 2018;26:67-73.

38. Al-Farsi M, Al-Amri A, Al-Hadhrami A, Al-Belushi S. Color, flavonoids, phenolics and antioxidants of Omani honey. Heliyon 2018;4:e874.

39. Kamal MM, Rashid MH, Mondal SC, Taj HF, Jung C. Physicochemical and microbiological characteristics of honey obtained through sugar feeding of bees. J Food Sci Technol 2019;56:2267-77.

40. Khalil I, Moniruzzaman M, Boukraâ L, Benhanifia M, Islam A, Islam N, et al. Physicochemical and antioxidant properties of Algerian honey. Molecules 2012;17:11199-215.

41. Cruz LC, Batista JE, Zemolin AP, Nunes ME, Lippert DB, Royes LF, et al. A study on the quality and identity of Brazilian pampa biome honey: Evidences for its beneficial effects against oxidative stress and hyperglycemia. Int J Food Sci 2014;2:1-11.

42. Frankel S, Robinson GE, Berenbaum MR. Antioxidant capacity and correlation characteristics of 14 unifloral honeys. J Apic Res 1998;37:27-31.

43. Neupane BP, Malla KP, Kaundinnyayana A, Poudel P, Thapa R, Shrestha S. Antioxidant properties of honey from different altitudes of Nepal Himalayas. Pol J Food Nutr Sci 2015;65:87-91

44. Mellen M, Fikselová M, Mendelová A, Haščík P. Antioxidant effect of natural honeys affected by their source and origin. Pol J Food Nutr Sci 2015;65:81-5.

45. Fikselová M, Kačániová M, Hleba L, Mellen M, Vukovič N, DžuganM. Antimicrobial and antioxidant activity of natural honeys of different origin. Anim Sci Biotechnol 2014;47:218-24. 